\title{
Association between Physical Activity and Insomnia among Saudi Female College Students
}

\author{
Einas Al-Eisa ${ }^{1)}$, Syamala Buragadda ${ }^{2 *}$, Ganeswara Rao Melam ${ }^{2)}$, Atheer O. Al-Osaimi ${ }^{2)}$, \\ Huda A. Al-Mubarak ${ }^{2)}$, Noura A. Al-Huwaimel ${ }^{2)}$ \\ 1) Female Centre for Science and Medical Studies, King Saud University, KSA \\ 2) Rehabilitation Health Sciences Department, College of Applied Medical Sciences, King Saud \\ University: Riyadh, KSA
}

\begin{abstract}
Purpose] Insomnia is quite common and it can affect the quality of life of an individual. Students undergo stress due to various academic demands leading to sleeplessness and daytime sleepiness. This study was conducted to investigate the association between physical activity and insomnia among female Saudi students. [Subjects] 62 female students with a mean age of $21 \pm 1.5$ years took part in a motivational program to increase the number of steps taken per day for three weeks. [Methods] After obtaining subject's informed consent all the subjects were assessed for insomnia using the insomnia severity index (ISI), They were then given pedometers to calculate the number of steps they took per day. A physical activity log was kept for three weeks. Pre- and post -intervention ISI scores were calculated and correlated with the 3 -week physical activity log. [Results] $50 \%$ of the subjects had no clinically significant insomnia (NCSI), $42 \%$ had sub threshold (STI), and $8 \%$ had moderate clinical (MCI) insomnia. There was a moderate negative correlation between physical activity and ISI scores after the 3- week motivation program. [Conclusion] Prevalence of insomnia was common among female Saudi students and increase in physical activity appears to improve the sleep pattern.

Key words: Sleep disorder, Insomnia, Physical activity
\end{abstract}

(This article was submitted May 15, 2013, and was accepted Jun. 20, 2013)

\section{INTRODUCTION}

Insomnia, which is difficulty with falling asleep, is more common among aged people. It was found that insomnia occurs in one-third of the general population leading to daytime sleepiness and mental disturbances. It has very serious impacts on individuals' health and psychological status which leads to anxiety, depression and poor performance ${ }^{1)}$. Studies have shown that insomnia is also more common among college students and can result in stress, depression and reduced academic performance ${ }^{2-6}$. Women report insomnia more frequently than $\mathrm{men}^{7,8)}$. Sleep disorders are one of the public health issues that need attention for prevention and early detection, as they are one of the causes of work absenteeism ${ }^{9)}$. Sleep is an individual process that differs from one person to another. Insomnia is defined by the presence of an individual's report of difficulty with sleep ${ }^{10)}$. Many tools are used to assess both quality and duration of sleep. Polysomnography and actigraphy are the objective methods. Subjective assessments includes self- reporting scales like the Pittsburgh Sleep Quality Index (PSQI), the

*Corresponding author. Syamala Buragadda (e- mail: syamala3110@yahoo.co.in)

(C)2013 The Society of Physical Therapy Science

This is an open-access article distributed under the terms of the Creative Commons Attribution Non-Commercial No Derivatives (by-nc-nd) License $<\mathrm{http}$ ://creativecommons.org/ licenses/by-nc-nd/3.0/>.
Insomnia Severity Index (ISI), the Women's Health Initiative Insomnia Rating Scale, the Basic Nordic Sleep Questionnaire, and the daily sleep log and anxiety index (STAI). The insomnia severity index is a valid, reliable and easy to administer tool ${ }^{11)}$. Insomnia can be treated by various pharmacological and non -pharmacological methods. Although pharmacological treatments are effective, they can cause adverse effects such as increased risk of falls, drowsiness, dizziness, cognitive impairment, somnolence, nausea, vomiting and motor vehicle crashes. Non pharmacological managements of insomnia include bright light therapy, stimulus control therapy, sleep restriction therapy, sleep hygiene education, cognitive therapy, relaxation therapy, paradoxical intention, and multi- component therapy ${ }^{12)}$. It has also been found that there is an association between regular exercise or physical activity and the prevalence rate of insomnia ${ }^{13)}$. Most studies have focused on management of clinical insomnia among the middle- aged and elderly, but the aim of our present study was to assess the level of insomnia among female college students, and to determine the association between their physical activity and the insomnia severity index.

\section{SUBJECTS AND METHODS}

After obtaining ethical committee approval multiple events were planned at the college of Applied Medical Sciences, King Saud University, Riyadh, to invite female graduate students to take part in this study. Activities like 
Table 1. Descriptive statistics of physical activity

\begin{tabular}{cccccc}
\hline & N & Minimum & Maximum & Mean & Std. Deviation \\
\hline Week 1 & 72 & 464.3 & $11,588.8$ & $5,458.6$ & 2.2 \\
Week 2 & 62 & 391.3 & $20,544.8$ & $5,368.7$ & 2.7 \\
Week 3 & 62 & 364.1 & $13,248.8$ & $4,733.3$ & 2.1 \\
\hline
\end{tabular}

Table 2. Relationship between ISI and sleep problem

\begin{tabular}{lcccc}
\hline \multicolumn{5}{c}{ Correlations } \\
\hline & Sleep problem & $\begin{array}{c}\text { Insomnia Severity } \\
\text { Index before }\end{array}$ & $\begin{array}{c}\text { Insomnia Severity } \\
\text { Index after }\end{array}$ \\
\hline \multirow{3}{*}{ Sleep problem } & Pearson Correlation & 1 & $-0.4\left(^{* *}\right)$ & $-0.3\left(^{* *}\right)$ \\
& Sig. (2-tailed) &. & 0.0 & 0.0 \\
Insomnia Severity & $\mathrm{N}$ & 78 & 72 & 65 \\
Index before & Pearson Correlation & $-0.4\left(^{* *}\right)$ & 1 & $0.7\left(^{* *}\right)$ \\
& Sig. (2-tailed) & 0.0 &. & 0.0 \\
Insomnia Severity & $\mathrm{N}$ & 72 & 72 & 64 \\
Index after & Pearson Correlation & $-0.3\left(^{* *}\right)$ & $0.7\left(^{* *}\right)$ & 1 \\
& Sig. (2-tailed) & 0.0 & 0.0 &. \\
\hline
\end{tabular}

posters, Face book events, broadcasts, and lectures were undertaken to motivate the students to participate in the walking program. One hundred and five volunteers as a sample of convenience were included and screened for the inclusion criteria. Subjects who had a history of fracture or surgery to the back, pelvis, or lower limb, any contraindications to increased walking, current complaints or conditions affecting their ability to walk, pregnancy or cardiopulmonary disorders were excluded. Subjects with a history of any medication were also excluded. Subjects with insomnia based on the ICSD-2 definition, which consists of frequent awakening and difficulty with falling asleep again, difficulty with falling asleep, waking too early, secondary day time impairment due to nighttime sleeplessness were included ${ }^{14)}$. Recruitment was done in four stages. In the first stage personal, medical, socioeconomic and academic details were collected and the ISI questionnaire and daily physical log were distributed. In the second stage we measured the BMI (body mass index). In the third stage, a seven- meter distance was taped on the floor to measure stride length, which was calculated by asking subjects to take 10 steps forward, 5 steps with each foot at their natural stride bringing the feet together with the last step. The stride length was calculated by dividing the distance covered by 10 . After recording stride length values, each subject was given a pedometer (Omron model HJ-152) in the final stage. Subjects were instructed to wear the pedometer at the level of the anterior superior iliac spine (ASIS) and also to fill in the daily physical activity log. Communication through e-mail and telephone were encouraged if any problem encountered. Out of the 105 volunteers, 33 were excluded, and there were 10 dropouts during the 3 -week motivation program, leaving finally 62 volunteers who successfully completed the study. The insomnia severity index (ISI) was used to assess the severity of insomnia. It is comprised of seven questions which are scored on a Likert scale ranging from 0 to 4 . The scores range from 0 to 28: 0 to 7, no clinically significant insomnia; 8 to 14 , sub- threshold insomnia; 15 to 21 , clinical insomnia (moderate); 22 to 28, clinical insomnia (severe). The ISI is a valid, reliable, and easy to administer questionnaire both as a screening tool and a measurement too ${ }^{11)}$. Pedometers are small devices that can be worn at the waist or ankle, and are capable of counting the number of steps taken $^{15}$. The participants were given an Omron (model HJ152) pedometer, and they recorded their total daily steps for three weeks.

\section{RESULTS}

Out of 105 volunteers, 80 subjects met the inclusion criteria, but only 62 could completed the study. Their mean age was $21 \pm 1.5$ years. Prevalence of insomnia: $50 \%$ of the subjects had no clinically significant insomnia (NCSI), 42\% had sub- threshold insomnia (STI), and $8 \%$ had moderate clinical insomnia (MCI). Physical activity log: the number of steps taken per day was recorded for 3 weeks. This encouraged the subjects to take as many steps as they could to improve their physical activity (Table 1). The results show that physical activity increased from the first to the third week. Association between insomnia and sleep problems: Pearson correlation analysis revealed a significant correlation between Sleep problem and the Insomnia Severity Index after the motivation program $(\mathrm{r}=-0.353, \mathrm{p}<0.01)$ (Table 2 ). Association between the number of coffee cups drunk and insomnia: Pearson correlation analysis of the Insomnia Severity Index before and after the motivation program with the number of coffee cups drunk per day showed a positive correlation with a value of $r=0.178$ and $(p=0.149)$ 
Table 3. Association between physical activity and ISI

\begin{tabular}{llcc}
\hline & & \multicolumn{2}{c}{$\begin{array}{c}\text { Correla- } \\
\text { tion }\end{array}$} \\
\hline Pair 1 & PA 1 \& ISI & 72 & -0.3 \\
Pair 2 & PA 3 \& ISI' & 66 & -0.3 \\
\hline
\end{tabular}

PA- physical activity in weeks 1 and 3

ISI-Insomnia Severity Index

which was not statistically significant. So, no association was found between caffeine intake and insomnia. Association between physical activity and insomnia: Physical activity measured as the number of steps taken correlated with the ISI values showing a moderately negative correlation, with values of $\mathrm{r}=-0.396$ at week 1 , and $\mathrm{r}=-0.378$ at week 3 (Table 3).

\section{DISCUSSION}

This is the first study conducted among Saudi female college students to have determined the association between their physical activity and insomnia. The results show that $50 \%$ had NCSI (no clinically significant insomnia), 42\% had sub- threshold insomnia and $8 \%$ had moderate clinical insomnia. The average number of steps taken increased from the first week to the third week. We found a mild negative correlation between physical activity and the insomnia severity index. This is consistent with earlier findings that exercise has a beneficial effect on sleep problems especially insomnia ${ }^{16)}$. Sleep regulates mood and affects learning, memory, concentration and recall, because it is one of the most important processes in a creature's life. On the other hand, poor sleep quality has adverse effects on learning, memory, and awareness adversely affecting work performance, especially among students. Students need to show a high level of performance, which may not be achieved with sleep disturbances, because higher mental functions would be affected, leading to unhappiness, irritability, tiredness, depression and decreased level of performance. In 1998, Sherrill et al. associated the level of physical activity and sleep disorders in the middle aged to elderly with obstructive lung airway disease. They reported that women have sleep disturbance and participate in exercise programs more than men, whereas men did regular vigorous activity, and walking at a brisk pace approximately 4.8 to 6.4 $\mathrm{km} / \mathrm{h}$. The effect of exercise on sleep is observed when it exceeds 1 hour in duration, and appears to be related to alteration of sleep architecture, e.g. frequency, duration, daytime sleep, quality etc ${ }^{13)}$. This is consistent with the results of our study that higher physical activity has beneficial effects on sleep quality. Researchers conducted a study of patients with end- stage renal disease in Saudi Arabia. They found that insomnia is common in dialysis patients and was significantly associated with other sleep disorders ${ }^{17}$. Previous studies also showed that sleep deprivation, and psychological stress are more common among medical students in other countries ${ }^{18-20)}$. Moderate intensity exercise improved sleep quality among post -menopausal sedentary women ${ }^{21)}$. Moderate intensity aerobic exercise reduced pre-sleep anxi- ety and improved the sleep of middle-aged and older patients with chronic primary insomnia ${ }^{22,23)}$. Previous studies have shown a strong relation between subjective assessment and objective assessment using polysomnography or actigraphy ${ }^{24,25)}$. The insomnia severity index (ISI) is considered a clinically reliable and valid tool in insomnia treatment research ${ }^{26)}$. Pedometers are considered the most valid and reliable tools for measuring physical activity ${ }^{27-30)}$. Our present study included a small sample size, and had only a 3-week motivational program for increasing the number of steps taken per day. As in most other studies, subjective assessment of insomnia was included. Physical activity was observed to be highest in the second week, and it gradually reduced in the third week. We recommend further research with a longer duration motivation program in a larger group to establish a stronger relationship between physical activity and insomnia.

\section{REFERENCES}

1) Léger D, Poursain B, Neubauer D, et al.: An international survey of sleeping problems in the general population. Curr Med Res Opin, 2008, 24: 307-317. [Medline] [CrossRef]

2) Kaneita Y, Ohida T, Osaki Y: Insomnia among Japanese adolescents: a nationwide representative survey. Sleep, 2006, 29: 1543-1550. [Medline]

3) Sing CY, Wong WS: Prevalence of insomnia and its psychosocial correlates among college students in Hong Kong. J Am Coll Health, 2011, 59: 174-182. [Medline] [CrossRef]

4) Angelone AM, Mattei A, Sbarbati M, et al.: Prevalence and correlates for self-reported sleep problems among nursing students. J Prev Med Hyg, 2011, 52: 201-208. [Medline]

5) Johns MW, Dudley HA, Masterton JP: The sleep habits, personality and academic performance of medical students. Med Educ, 1976, 10: 158-162. [Medline] [CrossRef]

6) Rodrigues RN, Viega SC, Esilva AA, et al.: Daytime sleepiness academic performance in medical students. Avg Neuropsiquiatr, 2002, 60: 6-11. [CrossRef]

7) Bartlett DJ, Paisley L, Desai AV: Insomnia diagnosis and management. Med Today, 2006, 7: 14-21.

8) Buysse DJ: Insomnia, depress, and aging: assessing sleep and mood interaction in older adult. Geriatric, 2004, 59: 47-52.

9) Chan-Chee C, Bayon V, Bloch J, et al.: Epidemiology of insomnia in France. Rev Epidemiol Sante Publique, 2011, 59: 409-422. [Medline] [CrossRef]

10) Roth T: Insomnia: definition, prevalence, etiology, and consequences. J Clin Sleep Med, 2007, 3: 7-10. [Medline]

11) Michael ST, Stephen WT: Measures of sleep: the insomnia severity index, Medical Outcomes Study (MOS) sleep scale, Pittsburgh Sleep Diary (PSD), and Pittsburgh Sleep Quality Index (PSQI). Am Coll Rheumatol, 2003, 49: 148-196.

12) Petit L, Azad N, Byszewski A, et al.: Non-pharmacological management of primary and secondary insomnia among older people: review of assessment tools and treatments. Age Ageing, 2003, 32: 19-25. [Medline] [CrossRef]

13) Sherrill DL, Kotchou K, Quan SF: Association of physical activity and human sleep disorders. Arch Intern Med, 1998, 158: 1894-1898. [Medline] [CrossRef]

14) Association A.A.D: International Classification of Sleep Disorders, Revised: Diagnostic and Coding Manuals. Rochester: American Sleep Disorders Association, 1997.

15) Mara Z, Vitolins, Cynthia SR, et al.: Measuring Adherence to Behavioral and Medical Interventions. Elsevier Science, 2000, 215: 188-149.

16) Leppamaki S, Haukka J, Lonnqvist J, et al.: Drop-out and mood improvement: a randomized controlled trial with light exposure and physical exercise. Bio Med Cent Psychiatry, 2004, 4: 22.

17) Al-Jahdali HH, Khogeer HA, Al-Qadhi WA, et al.: Insomnia in chronic renal patients on dialysis in Saudi Arabia. J Circadian Rhythms, 2010, 8: 7. [Medline] [CrossRef]

18) Lima PF, Medeiros AL, Araujo JF: Sleep-wake pattern of medical students: early versus late class starting time. Braz J Med Biol Res, 2002, 35: 1373-1377. [Medline] [CrossRef] 
19) Chan GC, Koh D: Understanding the psychosocial and physical work environment in a Singapore medical school. Singapore Med J, 2007, 48: 166-171. [Medline]

20) Abdulghani HM: Stress and depression among medical students: a cross sectional study at a medical college in Saudi Arabia. Pak J Med Sci, 2008, 24: $12-17$.

21) Tworoger SS, Yasui Y, Michael VV, et al.: Effects of a yearlong moderateintensity exercise and a stretching intervention on sleep quality in postmenopausal women. Sleep, 2003, 26: 830-836. [Medline]

22) King AC, Oman RF, Brassington GS, et al.: Moderate-intensity exercise and self-rated quality of sleep in older adults. A randomized controlled trial. JAMA, 1997, 277: 32-37. [Medline] [CrossRef]

23) Passos GS, Poyares D, Santana MG, et al.: Effect of acute physical exercise on patients with chronic primary insomnia. J Clin Sleep Med, 2010, 6: 270-275. [Medline]

24) Ohaeri JU, Odejide OA, Ikuesan BA, et al.: The pattern of isolated sleep paralysis among Nigerian students. J Natl Med Assoc, 1992, 84: 67-70. [Medline]

25) Loayza HMP, Ponte TC, Carvalho CG, et al.: Association between mental health screening by self-report questionnaire and insomnia in medical students. Arq Neuropsiquiatr, 2001, 59: 180-185. [Medline] [CrossRef]

26) Bastien $\mathrm{CH}$, Vallieres A, Morin CM: Validation of the insomnia severity index as an outcome measure for insomnia research. Sleep Med, 2001, 2: 297-307. [Medline] [CrossRef]

27) Tudor-Locke CE: Taking steps toward increased physical activity: using pedometers to measure and motivate. Res Dig, 2002, 3: 18 .

28) Tudor-Locke C, Williams JE, Reis JP, et al.: Utility of pedometers for assessing physical activity: convergent validity. Sports Med, 2002, 32: 795 808. [Medline] [CrossRef]

29) Talbot LA, Gaines JM, Huynh TN, et al.: A home-based pedometer-driven walking program to increase physical activity in older adults with osteoarthritis of the knee: a preliminary study. J Am Geriatr Soc, 2003, 51: 387-392. [Medline] [CrossRef]

30) Tudor-Locke CE, Myers AM, Bell RC, et al.: Preliminary outcome evaluation of the first step program: a daily physical activity intervention for individuals with type 2 diabetes. Patient Educ Couns, 2002, 47: 23-28. [Medline] [CrossRef] 